\title{
A STANDARDIZED COLOUR-VISION TESTING LANTERN (II) TRANSPORT TYPE
}

\author{
BY
}

\author{
L. C. Martiñ, D.I.C., A.R.C.S., D.SC. \\ ASSISTANT-PROFESSOR IN THE TECHNICAL OPTICS SECTION, \\ IMPERIAL COLLEGE OF SCIENCE AND TECHNOLOGY
}

THE purpose of this note is to describe a modification of the standardized colour vision testing lantern designed by the present writer (Martin, 1939), which should render it specially suitable for use by transport undertakings.

Experience has shown, however, that the mariner's test was a very satisfactory one in itself. Therefore the modifications are supplementary, and the marine form of the test can be carried out with the new form of the lantern if desired, as well as the "transport" tests.

The additions consist of an orange-yellow filter in addition to the original red, green, and white of the first form; so that pairs of "red with orange" and "orange with green" can be shown. Rail and road signals now employ orange signal lights extensively, and. on many grounds familiar to those dealing with the personnel to be tested it is desirable to make the test simulate practical conditions.

For practical trials, a selection of orange filter glasses was obtained from Messrs. Chance Bros. and Co. Ltd. and combined with suitable neutral filters so as to bring the intensity of the transmitted light to equality with that of the standard lights of the earlier lantern. Trial with the smallest apertures and standard conditions then showed that normal persons with good colour vision sometimes made mistakes ; for example a combination of "green-orange," i.e. "green with orange" might be called "green-red," or "orange-red " be called "white-red." It is therefore necessary when using the smallest apertures $(0.02$ in.) to restrict the lights shown to red, green, and white as in the well-established mariners' test ; and this is even more important when the modifying glasses are used with the small apertures.

Trial showed, however, that when the apertures were enlárged to 0.05 ins., the distinctions were very easy to normal vision, and this suggested the use of 0.04 . in. as a standard size for the pairs of apertures with which the supplementary part of the test can be conducted.

Experiments were made with a number of orange glasses and it appeared that, out of those available, a filter stated to have a hue wave-length of $5970 \mathrm{~A}^{*}$ was the most readily distinguished from

* With regard to a source at $2360 \mathrm{~K}$. . The true wave-length with regard to the lantern illuminant will be a' little smaller. 
the "white" on the one hand and red on the other. A transmission curve for this glass is appended. Reference to recent results on colour discrimination (for example Wright, 1941). shows this choice to be generally suitable. As regards filters used in practical signalling, British standard specification BSS 623 gave limits of

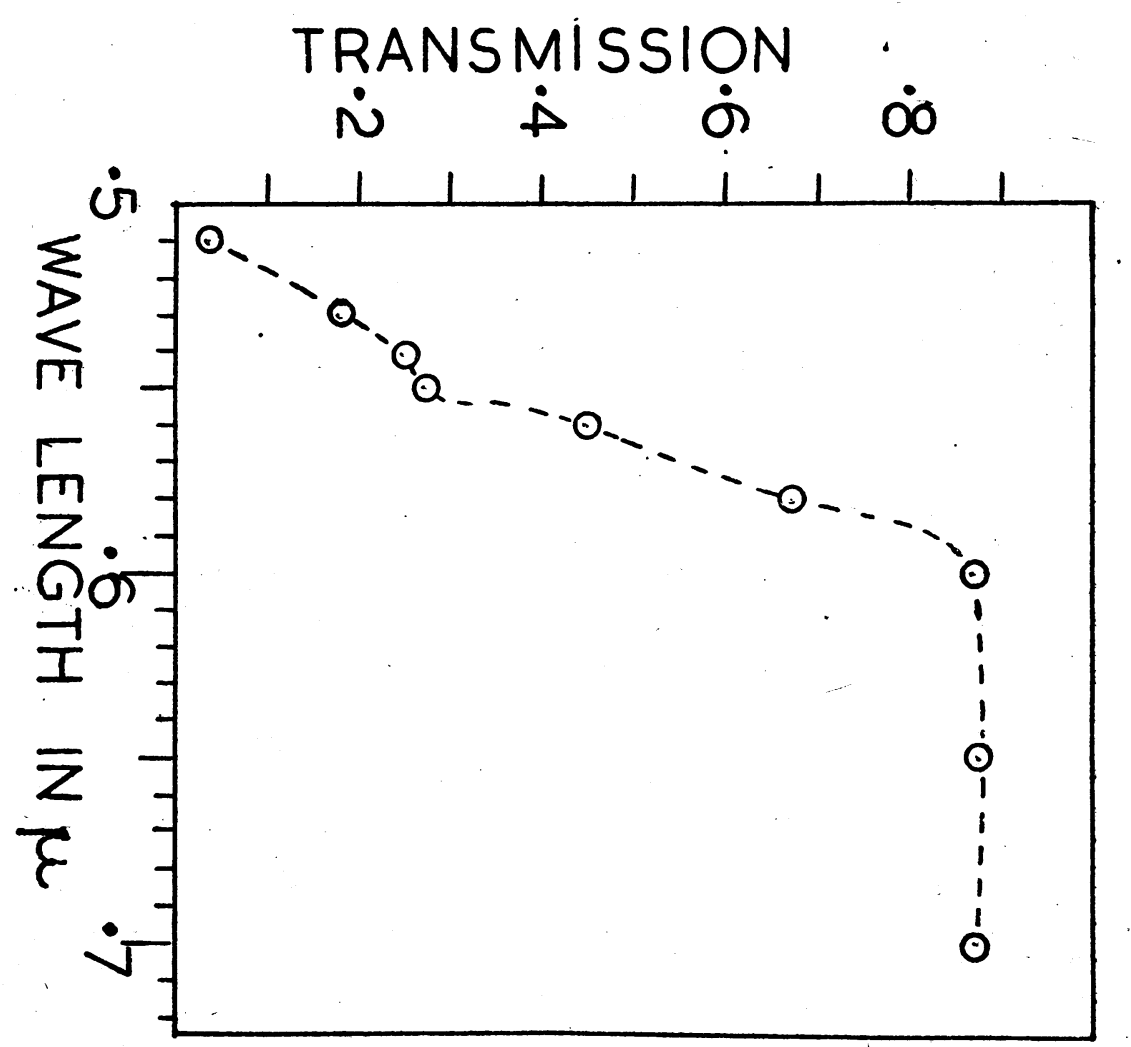

$5970 \mathrm{~A}$ to $5930 \mathrm{~A}$ for yellow glasses to be used with a lamp working at $2360^{\circ} \mathrm{K}$.

As regards angular subtense, the 0.04 ins. aperture seen at $20 \mathrm{ft}$. corresponds to a 4 in. railway lens seen at 667 yards, but the comparison is not particularly useful, owing to the relatively low brightness of the lantern, which gives the effect of a signal at a much greater distance. The 0.02 aperture naturally gives the effect of a doubled distance. In both cases the aperture is below the resolving limit of the eye (as seen from the standard distance of $20 \mathrm{ft}$.) so that the area effect is simply integrative.

As mentioned above, full trials have shown that no mistakes at all are expected from normal-sighted persons, with the large aperture 
$(0.04$ in.) even when "orange against green" has to be distinguished from "red against green:" Fortuitous mistakes sometimes occur due to nervousness or poor vision apart from colour defectiveness, but when confidence has been established the mistakes will not persist as in the case of genuine disturbance of colour vision. By the kindness of Dr. Graves Pierce of the L.M.S. Railway Medical Dept., the lantern was used by him in testing several persons who had already been tested by another lantern. All these appeared to be dichromats with severe colour defects, and the indications of the standard lantern were found to confirm this. Unfortunately owing to war conditions, detailed results are not available. Dr. Pierce found the test more "drastic" than the one usually applied, owing to the relative smallness of the apertures.

Owing to the present difficulties it has only been possible to obtain systematic results from three anomalous trichromats with a lantern which had been modified by substituting an orange filter for a red. It was then situated between another red and a green-so that red-orange and orange-green contrasts could be included in the series. The results shown in the table do not include those also taken with the dimming glasses in use, as these only confirmed the results which can be obtained with the full brightness.

\begin{tabular}{|c|c|c|c|c|c|c|c|c|c|c|}
\hline \multirow[t]{2}{*}{$\begin{array}{l}\text { Colour's } \\
\text { shown }\end{array}$} & \multirow{2}{*}{\multicolumn{2}{|c|}{$\begin{array}{c}\text { Mr. S. } \\
\text { Aperture } \\
0.04 \text { in. } \quad 0.02\end{array}$}} & \multirow{2}{*}{\multicolumn{4}{|c|}{$\begin{array}{c}\text { Mr. C. } \\
\text { Aperture } \\
0.04 \text { in. } \quad 0.02\end{array}$}} & \multicolumn{4}{|c|}{$\begin{array}{l}\text { Mr. W. } \\
\text { Aperture }\end{array}$} \\
\hline & & & & & & & 0.04 & & 0.02 & in. \\
\hline W G & $R \quad \mathrm{G}$ & $G \quad \mathrm{G}^{\circ}$ & $\mathrm{W}$ & $W$ & $G$ & G & $\mathrm{w}$ & $W$ & $R$ & G \\
\hline G & $\mathrm{G}$ & $\mathrm{G} \cdot \mathrm{G}$ & G & G & G & G & $W$ & $W$ & G & G \\
\hline $\mathrm{R}$ & $\mathrm{G}, \mathrm{R}$ & $G \quad R$ & G & $\mathbf{R}$ & G & $\mathbf{R}$ & $W$ & $\mathbf{R}$ & G & $\mathbf{R}$ \\
\hline W & $\mathrm{R} \quad G$ & $\mathrm{R} \quad G$ & $\mathrm{R}$ & $G$ & $\mathbf{R}$ & $G$ & $\mathbf{R}$ & W & $\mathbf{R}$ & $R$ \\
\hline w $\mathrm{W}$ & $G$ & $G \quad G$ & $G$ & $G$ & $G$ & $G$ & $R$ & $R$ & $G$ & $\boldsymbol{G}$ \\
\hline W $\mathrm{R}$ & $\mathrm{R}$ & $G \quad \mathrm{R}$ & $G$ & $\mathrm{R}$ & $G$ & $O$ & $\mathbf{w}$ & $\mathbf{R}$ & $G$ & $\mathbf{R}$ \\
\hline $\mathrm{R}$ & $G$ & $\mathrm{R} \quad G$ & $\mathrm{R}$ & $C$ & $\mathbf{R}$ & $W$ & $W$ & $W$ & $\mathbf{R}$ & $R$ \\
\hline G & $R$ & $G \quad \mathrm{G}$ & $G$ & $\mathrm{G}$ & $W$ & G & $W$ & G & $R$ & G \\
\hline w & $G$ & $G \quad G$ & G & $\mathrm{w}$ & $\mathrm{G}$ & w & $W$ & W & G & $R$ \\
\hline Mistakes & 8 & 8 & 7 & & & 8. & 10 & & $\varepsilon$ & 3 \\
\hline
\end{tabular}

The results show that the addition of the orange glass definitely increases the range of the test, as should be the case for candidates who ought to be able to distinguish orange in addition to red, green, 
and white. Needless to say, all the above candidates would fail to "pass"; the first two confuse "red-orange" with "red-green." Mr. C. is under difficulties even when allowed to approach the lantern as closely as possible; he named "orange-white" as "orangegreen" and "red-orange" as "two reds." However, in this he is unlike some candidates, who find their difficulties increase very greatly with diminished apparent area and brightness of the colours.

It may be suggested that no candidate is suitable for duties as a railway driver who fails repeatedly to pass the test with larger apertures without a mistake.

The colour filters of the modified Lantern as well as the old form, are all standardized and approved by the National Physical Laboratory according to specifications being deposited with the Medical Research Council.

In order to give a closer impression of railway signals, the Marine form of the Lantern is still used, but arranged with its general axis of symmetry horizontal, and the lights are seen vertically disposed instead of horizontally. The handle of the lantern acts as a foot in this arrangement.

Other changes in the new pattern of the Lantern have been introduced by the capable makers, Messrs. Kelvin, Bottomley and Baird, Ltd.

(a) The examiner's illuminating lamp has been removed from the. interior of the lantern; light from the volt-meter unit illuminates the examiner's writing pad.

(b) The base of the lantern has been perforated so that manipulation of the hand "capstan" wheel for changing the glasses is easy when the lantern is used on its side.

(c) A guard has been fitted over the opening so that the candidate cannot see the combination key-letters direct.

The tests suggested for transport undertakings are as follows :-

(1) A test with the eleven combinations including the orange using the larger apertures $(0.04 \mathrm{in}$.$) .$

(2) A test with the nine combinations excluding the orange using the smaller apertures.

For candidates making mistakes in the above, and requiring further tests:-repeat (1) and (2) using the modifying glasses.

It is expected that in practice, medical officers will find that part (1) above is sufficient, but it is not claimed at present that this test is established as satisfactory in the same sense as Part 2 with its years of proven utility. It is probably advisable that both parts should be used until full confidence in the adequacy of Part 1 is obtained. War conditions have prevented the full testing of Part (1) in the writer's laboratory, as the necessary border-line subjects are not easy to find; especially those with time to spare for tests.

There is every reason to adopt a severe test for entry to any 
service of a permanent character, since a matter of such importance is to be decided. There would seem to be every reason for an agreement on some standardized test which would prevent any candidate from passing in one form of test, spending years, perhaps, in training and then failing to pass a more drastic test in the end.

The assumption of responsibilites which a person is unfitted to bear is a grave mistake both on the part of the person himself, and those who allow him to do so. But if a test is strict it must be also just; the real disadvantage of cheap and untried tests is their variability. It is here that the chief possibility of injustice in colour vision testing is to be found. It looks, as if it should be easy to obtain a durable and consistent test; actually it takes a very great deal of care to make one. The present Lantern is an effort in that direction.

I am indebted, as before, to those whose help was acknowledged in the previous paper, and in addition to $\mathrm{Mr}$. $\mathrm{H}$. V. Walters for measuring the transmission of some of the filters ; also to Dr. Graves Pierce for the help mentioned above.

\section{REFERENCES}

MARTIN, Brit. Jl. Ophthal., Jan. 1939.

Wright (1941).-Proc. Phys. Soc., Vol. LV, p. 93.

\section{GLIOMA OF THE RETINA. A REVIEW OF TWELVE CASES*}

BY

W. B. E. MCCREA

DUBLIN

THIS communication is a clinico-pathological study, based on the twelve patients suffering from the so called glioma of the retina, treated in the Royal Victoria Eye and Ear Hospital, during the years 1938-42 inclusive. To clarify our ideas at the outset, it seems worth while to have some form of classification. I have followed that suggested by Sir Stewart Duke-Elder in his text-book. As he points out, in the present state of our knowledge, any classification can only be of a provisional nature. The divisions of the group are as follows :-

(a) Retinoblastoma-corresponding to the medulloblastoma of the brain. These comprise the great majority of "gliomata."

Received March 13, 1943. Read at Dublin Ophthalmological Society. February 24, 1943. 